\title{
Status of Ethnocentrism Among Public University Students in Ethiopia
}

\author{
AshebirDemekeGebretsadik $(\mathrm{PhD})^{1} \quad$ Belay Tefera Kibret $(\mathrm{PhD})^{2}$ \\ 1.Madda Walabu University, College of Education and Behavioral Studies,Department of Psychology, Bale \\ Robe, Ethiopia \\ 2.Addis Ababa University, College of Education and Behavioral Studies,School of Psychology, Addis Ababa, \\ Ethiopia
}

\begin{abstract}
Ethnocentrism does not accept cultural diversity, and is a general intolerance to out-groups and a relative preference for one's in-group over most out-groups. The literature suggests that ethnocentrism has the potential to lead to stereotypical prejudices and negative behaviours against out-groups or other ethnic group members (Donald \& Cindy, 2010). The purpose of this study was to investigate the status ethnocentrism and related factors among university students in Ethiopia. To achieve the objective of the study a cross-sectional research design was employed. A total of 771 participants (484 males and 287 females) were sampled from four government universities. The adapted measuring scale was Neuliep and McCroskey's (1997) and Neulip's (2002) Generalized Ethnocentrism Scale (GES). The combinations of multistage cluster sampling, stratified simple random sampling, simple random sampling and purposive sampling procedures were employed to select the sample participants. The data were analyzed using Descriptive Statistical Measures (Mean, SD, Quartile \& Percentile Scores), Frequency percentage, Chi-square, independent-t test and one-way ANOVA. The findings of the study depicted that the target group university students were labelled at lower level of ethnocentrism status. Furthermore, the findings indicated significant mean differences on ethnocentrism due to sex, place grown up and different batches of university students. However, there was no significant difference on ethnocentrism score between mono and mixed ethnic background of the participants. Finally, implications and recommendations were forwarded.
\end{abstract}

Keywords: Ethnocentrism, Status, University Students

DOI: $10.7176 /$ RHSS/10-13-03

Publication date:July $31^{\text {st }} 2020$

\section{Introduction}

The theme of ethnocentrism is not new phenomena to psychology, as it has been studied scientifically for more than a century. It is a human universal phenomenon. Ethnocentrism is believed by some scholars to be as old as the human race (Kasomo, 2010). In 1906, Sumner (1906) defined ethnocentrism as "the technical name for this view of things in which one's own group is the center of everything, and all others are scaled and rated with reference to it" (p. 13).Still Sumner's definition of ethnocentrism is widely accepted, the concept of ethnocentrism has evolved since its introduction.More recent definitions conceptualize ethnocentrism as belief, conscious or unconscious, that one's own cultural experiences, values, and assumptions are normal. What is different is defined in relation to that self-referential worldview (Collins \& Arthur, 2010). Ethnocentrism forms the basis for various other isms- racism, heterosexism, sexism, and so on. In this case the otheris defined as lesserin some way (Fowers\&Davidov, 2006).

Hollister and Boivin cited in Demewoz (1997) showed that ethnocentrism could be defined in variety of ways. It ranges from the notion that one's ethnic group is culturally and biologically superior to all others in most important aspects to the tendency to project cultural stereotypes and stigmas upon ethnic background in overtly hostile manner. According to them, ethnocentrism was defined as unwillingness to engage in social interactions with other ethnic groups to the same extent as with own ethnic group. Fowers\&Davidov (2006) also asserts that the nature of the "we - they" attitude associated with the term and it constitutes a general rejection of all out groups and an over evaluation of one's own ethnic group.

Throughout its conceptualization, it is clear that both positive and negative attributes exist in the concept of ethnocentrism. For example, sports teams, families, and even academic fields may fall within a broad conceptualization of ethnocentrism as it relates to team-building, or in-group development. On another hand, for people that have differing cultural or ethnic backgrounds, and that come in contact with one another, the struggles of ethnocentrism are great. From this, the communication of ideas and meanings of messages are often, proverbially, lost in translation (Justen, 2009).

Sumner (1906) also compared ethnocentrism with patriotism, as he said, "ethnocentrism leads a people to exaggerate and intensify everything in their own culture which is peculiar and which differentiates them from others; it therefore strengthens the culture" (p. 13). In accordance with this thought of enhanced nationalistic pride or patriotism (Wrench, et al., 2006), ethnocentrism, in low levels, also aids in-group development allowing for a more decorous level of group cohesion. 
In general, as a human universal reality, ethnocentrism is said to be more pronounced in modern world than in pre-literate "tribes" (Justen, 2009).

\section{Factors for Ethnocentrism}

Ethnocentrism is generally viewed as lacking acceptance of cultural diversity and intolerance for out-groups (Donald \& Cindy, 2010). This lack of acceptance of cultural diversity has a strong tendency to lead to negative stereotypes toward other cultural/ethnic groups, negative prejudice and negative behaviours against these group members. Such an attitude might form the bases for interethnic conflict.

Different authors forwarded various causes for ethnocentrism. These may be personality characteristics, stereotypic belief, motivational factors, sociological/socio-cultural factors, status, majority-minority status, socially desirable response, intimacy, the attitude-behaviour gap and the like.

Personality traits: is considered to be responsible for ethnocentrism. Hewstone (1985) reported that a person who is unable to love self is also unable to love others. Stephan and Rosenfield (1978) asserted that more positive attitudes towards in-group than out-group members supports the contention of authoritarian personality theorists that prejudiced individuals tend to have generalized prejudices that are directed towards all out-groups. Stereotypic belief: also serves as categorization function (Bhawuk and Brislin, 1992). Such results may be due to cultural stereotypes of the out group (Collins \& Arthur, 2010). In line with this, there is an over evaluation of one's ethnic group as culturally and biologically superior to all others in most important aspects (Bhawuk and Brislin, 1992).

Socio-cultural characteristics: the social environment determines or at least structures what people do, feel, and think (Verkuyten, 2005). With regard to socio-cultural influences Heine (2008) reported that both sociological and cultural factors may be associated with ethnic prejudice.

Status: sometimes unequal status in every aspect may result in ethnocentric attitude. For instance, " unequal status contact" where in the Americans look down the Greeks because the Greeks are considered as less successful in reaching shared cultural goals in USA (Triandis, 1977). Sharma (1992) also implied that low achieving students were found to be more likely to have high ethnic biases. As well senior level college students were found significantly less ethnocentric than freshman, the explanation that educational status is likely to have a significant impact on ethnocentric attitude (Hollsiter and Boivin, 1987). On other hand over-representation in the university may contribute for positive intergroup differentiation, students of ethnic minority may be more ethnocentric than those of the majority students (Hewstone, 1985).

Motivational factors: motivation is also an important determinant for inter-ethnic attitude. This may be because of strong interest in linguistic, economic and cultural domination. These interests pointed out as sources of major conflict in many areas of the world (Wolff, 2006). Particularly scarce resources initiate such an attitude and practice as well.

Socially desirable response: in relation to this, social desirability effects in rating have its own impact on ethnocentric attitude (e. g. The way African Americans rated by university students) (Hollsiter and Boivin, 1987). In study conducted by Hewstone (1985), Chinese community given their security and status in that multicultural society (USA) and overrepresentation in the university and in big business perhaps makes them felt no need for positive intergroup differentiation.

In general the in-group favoritism may come as a result of many factors and which in turn has a strong tendency to lead to negative stereotypes toward other culture/ethnic groups, negative prejudice and negative behaviours against other group members. Such an attitude might form the bases for interethnic conflicts.

In contemporary Ethiopia, the issues of ethnicity, ethnic autonomy, multiculturalism and ethnocentrism are highly popularized than earlier times. Particularly in higher education institutions (colleges and universities) where young people of many ethnic backgrounds, social class, religious and political affiliations come together in campuses students are expected to live in the same dormitories and learn together in the same classrooms and collaborate in university organizations, social activities, sports, and cultural festivals and events. Nevertheless, sometimes unwise exposure to ethnic diversity in higher learning educations brings experience of ethnic prejudices, cultural ethnocentrism, feeling of distrust and intergroup conflicts. This is true that these days and in the past, in universities in Ethiopia, it has become common news to hear that students of one ethnic group are being in clashed with students from another ethnic group (or other ethnic groups). Studies conducted in some universities like Addis Ababa, Hawassa, Adama and others have accounted unhealthy relationship among some sections of students especially between those from the dominant ethnic groups such as Oromo, Amhara and Tigray is common (Abera H., 2010; Abera T., 2010; Asefa, 2009; Tilahun, 2007). More often than not minor disputes between individuals escalate into a bigger fighting which involves students aligned along ethnic lines (Abera H., 2010; Tilahun, 2007).

Similarly, Demewoz (1997) reported that there is a tendency of ethnocentric attitude among Addis Ababa University students of Amhara, Oromo, Tigray and Guragie ethnic groups. By and large this ethnocentric attitude leads to interethnic prejudice, feeling of distrust, intolerance and intergroup conflict among university 
students (AberaHailemariam, 2010; AberaTeferi, 2010; Demewoz, 1997).

Despite the facts, the topic of ethnocentrism and related concepts are researchable in Ethiopia particularly in higher learning institutions; to the best knowledge of the investigator there is no study that profoundly deals about the status of ethnocentrism and related issues among university students in Ethiopia.

Actually some attempts are made to study the issues belonging to different ethnic groups, especially about the minorities and college students (Abera H., 2010; Abera T., 2010; Tilahun, 2007; Birhanu, 2007; Demewoz, 1997). However, these studies have some limitations. They have been executed on few segments of ethnic groups, particularly focused on the dominant ethnic groups in the country such as Amhara, Oromo, Tigrie and Guragie. In addition, many of them have been studied on few individuals through qualitative investigations.In general, researches on the topics in Ethiopia are fragmentary and inconclusive. Therefore, the purpose of this study was to investigate the status ethnocentrism and related factors among university students in Ethiopia.

\section{Research Questions}

1. What is the status ofethnocentrismamong Ethiopian university students?

2. Is there significant mean difference in ethnocentrism score among public university students in Ethiopia due to sex, ethnic background, place where grown up, and year in university (batches)?

\section{MaterialsandMethods}

The study is principally organized around a cross-sectional survey research design. Data was collected from four Universities namely Adama Science and Technology University, Addis Ababa Science and Technology University, Addis Ababa University, and MaddaWalabu University. The universities were purposefully selected from various generations and sizes of universities. Four universities from different categories instead of one is primarily preferred in this study for the reason that including more than one case gives more power to the analysis and findings in terms of getting comprehensive and rich data. Furthermore, in most government universities in Ethiopia at different episodes, interethnic conflicts among university students have been reported in these Universities.

\section{Population, sampling procedures and sample}

The target population of this study has been university students of regular program of both sexes from different ethnic backgrounds of Addis Ababa Science and Technology, MaddaWalabu, Adama Science and Technology and Addis Ababa universities. The total population of the study during the study period was 47, 150.The combinations of multistage cluster sampling, stratified simple random sampling, simple random sampling and purposive sampling procedures were employed to select respondents. The survey has used the single population proportion formula to determine the sample size.

In order to address non-responses, the sample size had increased by a non-response insurance factor. Thus, allowances of $10 \%$ non-response rate make a total sample of 421 . Furthermore, the single population proportion formula is valid only for simple random or systematic random sampling method; but the sampling technique that is used for this study is multistage cluster sampling technique. Therefore, the calculated sample size has to be multiplied by $\mathrm{D}$ which is the design effect resulting with $\mathrm{N}=$ Dn where $\mathrm{N}$ is the sample size for cluster sample, $\mathrm{n}$ is the sample size obtained from the calculation and D is the design effect. The design effect (D) provides a correction for the loss of sampling efficiency resulting from the use of multi stage cluster sampling instead of simple random sampling. Hence, by considering the design effect of 2 the number had been multiplied by 2 and the total number of students taken for the study was 842 .

\section{Instruments for the study}

To achieve the objectives of this study, the required and relevant information was gathered through questionnaire. The Amharic and English versions of the questionnaire were used.

\section{Questionnaire preparation, validation process, and data gathering procedures}

To measure ethnocentrism, Neuliep and McCroskey's (1997) and Neulip's (2002) Generalized Ethnocentrism Scale (GES) was used in a five-point Likert measurement (1 strongly disagree, 2 disagree, 3 undecided, 4 agree, 5 strongly agree) for self-reported data. This scale is designed to assess people's feelings regarding their culture and ethnic group. The statements included in the scale such as "Most other ethnic groups cultures are backward compared to my culture", "My ethnic group culture should be the role model for other cultures", and "Other cultures should try to be more like my culture". The scale originally had 22 questions, but was reviewed for face validity and four questions were changed to avoid double-barrel questions (I am very interested in the customs and values of othercultures; I am not interested in the customs and values of other cultures; I have littlerespect for the customs and values of other cultures; I respect the customs and values ofother cultures). Thus, four additional questions were added to include both customs and values separately. Accordingly three items were 
dropped by judges for redundancy and vagueness. The alpha reliability coefficient of the original scale was 0.89 . The pilot study was conducted in MaddaWalabu University on 50 Male and Female regular undergraduate students which were not included in the main study. Theinternal consistency of the scale improved from $\alpha=.858$ during pilot study to $\alpha=.861$ on the main study. The Cronbach's alpha score on this scale was also high.

In data collection, eight data collectors (two from each university) who have previous experience in data collection were recruited. Training was given on the questionnaire and data collection techniques. Data collectors had distributed the questionnaire to the students, remained in the classroom during administration and transported the completed questionnaire from the universities.

Procedurally, both the Amharic and English versions of the same questionnaire were given to the respondents and invited to fill out the one they prefer. The average response rate for this study was $92 \%$.

\section{Methods of data analyses}

After the responses on the questionnaires have been collected, SPSS version 21.0 was used to enter, clean, and analyze the collected data. Answer sheets were excluded from entry if respondents failed to complete at least half of the questionnaire.To answer the research questions, descriptive statistics (the mean, SD, variance, quartile and percentile scores), frequency percentages, Chi-square $(\chi 2)$, pairwise chi-square comparisons, independent $t-$ test and one-way ANOVA were computed. Confidence intervals of $95 \%$ were used to see the precision of the study.

\section{Results and Discussions}

Socio-demographic Context of Participants of the Study

Table 1: Socio-demographic Characteristics of Participants of the Study

\begin{tabular}{|c|c|c|c|}
\hline Variables & & Frequency & Percent \\
\hline $\operatorname{Sex}(n=771)$ & $\begin{array}{l}\text { Male } \\
\text { Female }\end{array}$ & $\begin{array}{l}484 \\
287\end{array}$ & $\begin{array}{l}62.8 \\
37.2\end{array}$ \\
\hline $\operatorname{Age}(n=765)$ & $\begin{array}{l}18-21 \\
22-25 \\
26 \& \text { above }\end{array}$ & $\begin{array}{l}430 \\
243 \\
92\end{array}$ & $\begin{array}{l}55.8 \\
31.5 \\
11.9\end{array}$ \\
\hline Ethnicity $(n=771)$ & $\begin{array}{l}\text { Oromo } \\
\text { Amhara } \\
\text { Tigrie } \\
\text { SNNP } \\
\text { Somali } \\
\text { Others } \\
\text { Not Identified }\end{array}$ & $\begin{array}{l}202 \\
239 \\
76 \\
108 \\
10 \\
12 \\
124 \\
\end{array}$ & $\begin{array}{l}26.0 \\
31.0 \\
9.9 \\
14.0 \\
1.3 \\
1.6 \\
16.1 \\
\end{array}$ \\
\hline Ethnic background(n=761) & $\begin{array}{l}\text { Single(mono) } \\
\text { Mixed }\end{array}$ & $\begin{array}{l}456 \\
305 \\
\end{array}$ & $\begin{array}{l}59.1 \\
39.6 \\
\end{array}$ \\
\hline Religion $(n=765)$ & $\begin{array}{l}\text { Orthodox Christian } \\
\text { Muslim } \\
\text { Protestant } \\
\text { Catholic } \\
\text { Others } \\
\text { Non-religious }\end{array}$ & $\begin{array}{l}465 \\
102 \\
154 \\
12 \\
20 \\
12 \\
\end{array}$ & $\begin{array}{l}60.3 \\
13.2 \\
20.0 \\
1.6 \\
2.6 \\
1.6\end{array}$ \\
\hline Place grown up $(n=769)$ & $\begin{array}{l}\text { Rural } \\
\text { Urban }\end{array}$ & $\begin{array}{l}255 \\
514\end{array}$ & $\begin{array}{l}33.1 \\
66.7\end{array}$ \\
\hline Year in the University $(n=771)$ & $\begin{array}{l}\text { First Year } \\
\text { Second Year } \\
\text { Third Year } \\
\text { Fourth year and above }\end{array}$ & $\begin{array}{l}182 \\
142 \\
212 \\
235 \\
\end{array}$ & $\begin{array}{l}23.6 \\
18.4 \\
27.5 \\
30.5 \\
\end{array}$ \\
\hline
\end{tabular}

As indicated in Table 1, a total of 771 regular undergraduate university students have been included from four government universities. The sex distribution of participants was: 484 (62.8\%) male and $287(37.2 \%)$ female. The age of the participants ranges 17 to 36 (a mean age of 19.23 years). The majority of students, 430 $(55.8 \%)$ were in between 18 to 21 years old and the remaining $243(31.5 \%)$ and $92(11.9 \%)$ of them were found between 22-25 and $26 \&$ above years old respectively. As it is indicated in the above table, $456(59.1 \%)$ of the respondents said they are from single (mono) ethnic background whereas $305(39.6 \%)$ of them said they are from mixed ethnic group i.e. their parents were from different ethnic background. Two hundred two (26\%) of the respondents identified themselves as Oromo ethnic group whereas 239 (31.0\%) of them were belongs to Amhara ethnic group. Furthermore, $108(14 \%)$ and $76(9.9 \%)$ were belongs to SNNP and Tigray ethnic groups 
respectively. Considerable number of respondents, $124(16.1 \%)$ were not or didn't like to identify their particular ethnic group.

From the total sample, $465(60.3 \%)$ of them were belonged to Orthodox Christians while Protestants and Muslims constitutes $154(20.0 \%)$ and $102(13.2 \%)$ of the total respondents respectively. Others religions mentioned were Catholic $12(1.6 \%)$ and some minor churches $20(2.6 \%)$, while only a few of $12(1.6 \%)$ stated to have no religious affiliations at all.

Five hundred fourteen $(66.7 \%)$ of the respondents identified themselves as they are affiliated to urban background whereas $255(33.1 \%)$ of them were from rural. There was somehow similar distribution across batches (years in university). One hundred eighty two $(23.6 \%)$ of them were freshmen, $142(18.4 \%)$ of them were second year and $212(27.5 \%)$ were third year while the remaining $235(30.5 \%)$ were fourth year and above.

\section{Ethnocentrism Status of University Students}

One of the aims of this study was to determine the ethnocentrism status of university students. Table 2 displays a descriptive summary of the rating scores of respondents using mean, variances, SD and percentile scores and its description to suggest on the intercultural sensitivity status of university students.

Hence, in order to attest the ethnocentrism status; percentile scores was utilized to determine the cut-off scores for the different categories. The mean scores on normal curve below $25^{\text {th }}$ percentile score stand for low status, while the mean scores above $75^{\text {th }}$ percentile scores signify the highest status. The mean scores between the $25^{\text {th }}$ and $75^{\text {th }}$ percentile scores denotes medium level of ethnocentrism.

Table 2: Descriptive Statistical Values on Ethnocentrism Score

\begin{tabular}{|c|c|c|c|c|c|c|c|c|c|}
\hline \multirow[b]{2}{*}{ Variable } & \multirow[b]{2}{*}{ Nof items } & \multirow[b]{2}{*}{ Mean } & \multirow[b]{2}{*}{ Variance } & \multirow[b]{2}{*}{$S D$} & \multirow[b]{2}{*}{$\operatorname{Max}$} & \multirow[b]{2}{*}{ Min } & \multicolumn{3}{|c|}{ Percentile Scores } \\
\hline & & & & & & & $25^{\text {th }}$ & $50^{t h}$ & $75^{\text {th }}$ \\
\hline Ethnocentrism & 20 & 40.27 & 156.82 & 12.52 & 90.00 & 20.00 & 31.00 & 39.00 & 49.00 \\
\hline
\end{tabular}

The descriptive summary of the observed mean score of ethnocentrism of minimum scores (1x items 20) $=20$, stands for lowestethnocentrism. Similarly, the average scores forethnocentrism rating scores is $(3 \times 20$ items $)$ $=60$ stands for middle level ethnocentrism. While the highest $(5 x$ items 20$)=100$, expected scores on ethnocentrism suggests for the highest status of ethnocentrism of university students.

Accordingly,rating score of ethnocentrism scale provides that the observed mean score $(\mathrm{M}=40.27)$ is quite lower than the expected average (60). Note that even the highest $75^{\text {th }}$ percentile score $(49.00)$ is lower than the expected average (60). These figures may suggest that the university students involved in this study has labelled at lower status of ethnocentrism. In another words, they are not exhibited a tendency of ethnocentric attitude and behaviour.

Furthermore to verify the above information, based on the total rating scores on ethnocentrism scale, it is possible to label the ethnocentrism status of participants of the study into higher, middle and lower level by using the total scores exhibited. And subsequently it is possible to assign the participants to one of the three aforementioned orientations. Relying on the rating scores of respondents (who said strongly disagree and disagree) on ethnocentrism scale, the lower score 20-60 stands for lower level of intercultural sensitivity of university students. Similarly, the expected middle scores (scores between disagree and agree) intercultural sensitivity (61-80) on scale stands for middle level of ethnocentrismof university students. Whilst the higher (who said agree and strongly agree) expected score 81-100 on ethnocentrismscale suggests for the higher level of intercultural sensitivity of university students.

Table 3: Descriptive Frequency, Chi-square and Pairwise Chi-square Comparisons on Intercultural Sensitivity Score across Different Levels

\begin{tabular}{|c|c|c|c|c|c|c|c|c|c|}
\hline \multirow[t]{2}{*}{ Variable } & \multirow[t]{2}{*}{ Levels } & \multirow[t]{2}{*}{ Freq. } & \multirow[t]{2}{*}{ Percent } & \multirow[t]{2}{*}{$\overline{d f}$} & \multirow[t]{2}{*}{$\chi^{2}$} & \multicolumn{4}{|c|}{$\chi^{2}$ (Pairwise Comparisons) } \\
\hline & & & & & & (I) Level & (J) Level & df & $\chi^{2}$ \\
\hline \multirow{5}{*}{ Ethnocentrism } & Lower (20-40) & 443 & 57.5 & \multirow{5}{*}{2} & \multirow{5}{*}{$401.14 *$} & Lower & Middle & 1 & $18.46^{*}$ \\
\hline & Middle (41-79) & 324 & 41.6 & & & Middle & Higher & 1 & $312.20^{*}$ \\
\hline & \multirow{2}{*}{ Higher (80-100) } & 4 & .5 & & & & & & \\
\hline & & & & & & \multirow[t]{2}{*}{ Higher } & \multirow[t]{2}{*}{ Lower } & \multirow[t]{2}{*}{1} & \multirow[t]{2}{*}{$431.14^{*}$} \\
\hline & Total & 771 & 100 & & & & & & \\
\hline
\end{tabular}

Note: $* P<0.05$

Taking into account the above descriptions, as shown in Table 3, significantly higher number of participants of the study $57.5 \%(\chi 2=401.144, \mathrm{p}<0.05)$ were categorized under lower level of ethnocentrism.

Furthermore as indicated in Table 3, pairwise comparisons were conducted among the frequencies on different levels of ethnocentrism. The pairwise ad hoc analyses for all comparisons revealed significant differences among the three levels of the variables.

Thus, from the above descriptions it is said that university students who participated in the study are less 
ethnocentric.Consistent to this study, an earlier local study on students in the former Be-ede Mariam School and Hailesellasie I University (Ziegler, 1972), has found that those subjects had not been ethnocentric in the strictest sense of the term. This is attributable to the then aspiration of unity among students had been strong. Habtamu, Hallahmi\&Abbink (2001) also investigated that good and positive relationship has been exhibited among various ethnic groups' young adult college and high school students in Ethiopia. This finding is incongruent with the reports (AberaHailemariam, 2010; AberaTeferi, 2010; Asefa, 2009, Demewoz, 2001; 1997) that university students in Ethiopia exhibited more negative intergroup attitude, misunderstanding among ethnic groups, greater desire to avoid interethnic interactions, suspicious to each others and more ethnocentric. Actually, the above mentioned studies are conducted on few segments of "the dominant ethnic groups" in the country such as Amhara, Oromo, Tigre and Guragie.

\section{Group Differences on EthnocentrismScores}

One of the objectives of this study is to investigate whether there is a significant group difference in ethnocentrismscore among university students across respondents' sex, ethnic background, place where grown up and batches. Accordinglyto verify this, independent t-test analysis, one-way ANOVA and mean comparisons were performed and results obtained from group comparisons are presented as follows:

\section{Sex Difference on Ethnocentrism Scoreamong University Students}

Table 4: - Sex Difference in Ethnocentrismamong University Students (Independent T-Test)

\begin{tabular}{|c|c|c|c|c|c|c|c|}
\hline Dependent Variables & Sex & N & Mean & SD & df & t- obtained & Sig. \\
\hline \multirow{2}{*}{ Ethnocentrism } & $\mathrm{M}$ & 484 & 41.19 & 12.18 & & & \\
\cline { 2 - 9 } & $\mathrm{F}$ & 287 & 38.72 & 12.95 & 769 & 2.66 & 0.008 \\
\hline
\end{tabular}

Results shown in Table 4, an independent-samples t-test was conducted to compare the ethnocentrismscores for males and females. There was significant mean difference in scores for males $(M=41.19, S D=12.18)$ and females $[M=38.72, S D=12.95 ; t(769)=2.66, p=.008]$. This indicates that male university students are more ethnocentric than females. This is consistent with Demewoz's (1997) study on ethnocentrism and peer relation among Addis Ababa University students which revealed a statistically significant difference between males and females on ethnocentrism.In this study the mean scores reveal that female university students are less ethnocentric than their male counterparts. One possible convincing reason for this difference could be associated with empathetic nature of girls/women, cultural and earlier socialization impact on children as male and female child rearing practices in Ethiopia. For instance Belay (2008) indicates that girls are usually rebuked so as to loud their voice for identity outside the cage in the public sphere.

Ethnic Background Difference in Ethnocentrismamong University Students

Table 5: - Ethnic Background Difference in Ethnocentrismamong University Students (Independent T-Test)

\begin{tabular}{|c|c|c|c|c|c|c|c|}
\hline Dependent Variables & Ethnic background & $\mathrm{N}$ & Mean & SD & $\mathrm{df}$ & t- obtained & Sig. \\
\hline \multirow[t]{2}{*}{ Ethnocentrism } & Mono & 456 & 39.97 & 11.91 & \multirow[b]{2}{*}{759} & \multirow[b]{2}{*}{.798} & \multirow[b]{2}{*}{.425} \\
\hline & Mixed & 305 & 40.71 & 13.38 & & & \\
\hline
\end{tabular}

Results depicted in Table 5 reveals that there was no significant mean differences are observed between single/mono $(M=39.97, S D=11.91)$ and mixed ethnic background $(M=40.71, S D=13.38)$ on ethnocentrism, $t(759)=-.798, p=.425$. Thus, this result would suggest that university students in Ethiopia from single/mono and mixed ethnic background have no difference in their ethnocentrism score. This result is not supported by findings of Stephan \& Stephen (1991) that "there are some positive effects of bicultural socialization in terms of insulation from the ethnocentrism of single - heritage groups" (p. 248). This might be because of that dual heritage multiethnic (mixed ethnic) increases the likelihood that they will have a close contact with at least two cultures, these individuals may function as a bridge between the groups. Even mixed ethnic individuals who live in a monoethnic community and consider themselves to be members of one ethnic group are probably less ethnocentric than monoethnic individuals. People who identify with and participate in two cultures may further the appreciation of diversity and reduction of interethnic intergroup conflicts (Phinney\&Alipuria, 1996; Stephan \& Stephen, 1991). In this study, data on ethnic composition indicate that $39.6 \%$ of the participants have been from mixed ethnic group i.e. their parents were from at least two different ethnic backgrounds.

Residential Background Difference in Ethnocentrismamong University Students Table 6:- Residential Background Difference in Ethnocentrismamong University Students (Independent T-Test)

\begin{tabular}{|c|c|c|c|c|c|c|c|}
\hline Dependent Variables & Residential Background & $\mathrm{N}$ & Mean & SD & df & t- obtained & Sig. \\
\hline \multirow{2}{*}{ Ethnocentrism } & Rural & 255 & 43.07 & 14.31 & & & \\
\cline { 2 - 7 } & Urban & 514 & 38.83 & 11.28 & 767 & 4.478 & .000 \\
\hline
\end{tabular}


To verify whether there is a significant difference between rural and urban background university students on ethnocentrism score,an independent t-test result and mean scores displayed in Table 6 revealed a statistically significant mean difference observed between rural and urban background students rural $(M=43.07, S D=14.31)$ and females $[M=38.83, S D=11.28 ; t(767)=4.478, p=.000]$. These results imply that rural university students are more ethnocentricthan urban background university students. The result may support the findings of Stephan \& Stephen (1991) that "there are some positive effects of bicultural socialization in terms of insulation from the ethnocentrism of single heritage groups" (p. 248). Since urban areas usually dwelled by dual heritage multiethnic (mixed ethnic) groups which increases the likelihood that they would have close contact with at least two cultures (ethnic groups), these individuals may function as a bridge between groups. In the present study, it is evident that data on ethnic composition of urban background university indicate that from the total 305 (39.6\%) of the participants drawn from mixed ethnic group, 249 (82\%) of them are urban background.

\section{Ethnocentrismamong University Students across different Batches}

This study also determined whether years of stay in university has made a difference onethnocentrismscore among students. One-way ANOVA has been employed and is presented as follow:

Table 7: - Summary Table of one-way ANOVA

\begin{tabular}{|l|r|r|r|r|r|}
\hline & Sum of Squares & \multicolumn{1}{c|}{ df } & Mean Square & F & Sig. \\
\hline Between Groups & 3748.164 & 3 & 1249.388 & 8.190 & .000 \\
Within Groups & 117001.543 & 767 & 152.544 & & \\
Total & 120749.707 & 770 & & & \\
\hline
\end{tabular}

ANOVA test indicated in Table 7, reveal that there is significant differences across batches on ethnocentrism score, $\mathrm{F}(3,767)=8.190, \mathrm{P}=.000$. An examination of the mean scores disclosed that first year university students exhibited higher on ethnocentrism scale $(M=43.54, S D=7.71)$ than the other batches, second year students scored $(M=37.76, S D=11.68)$ and third year $(M=41.14, S D=11.09)$, fourth year and above $(M=38.49, S D=13.31)$.

In addition to an analysis of one-way ANOVA above, mean comparison Post hoc analysis of Tukey's procedure were performed for the significant differences among different batches have been exhibited. For the significant difference, the difference between the first and the second and $4^{\text {th }}$ year and above is attributed for the differences. In general, the results of these analyses provide that first year university students are more ethnocentric than other batches. This may suggest thatfreshmen students may busy with searching for their ethnic identity and attached to inner group than outer group than senior class students. This result is consistent with the finding that senior level college students are found significantly less ethnocentric than freshman (Hollsiter and Boivin, 1987).

\section{Conclusions}

The findings of the study, rating score on ethnocentrism scale provided lower mean score than the expected average or the majority of the participants are categorized at lower ethnocentrism status. This may hint that respondents of the university students do not exhibit a tendency of ethnocentric attitude and behaviour.Thus it is possible to conclude that university students included in the studywere not ethnocentric.

As per this research finding, statistically significant mean differences are found between males and females in their ethnocentrism score. Female university students are less ethnocentric. Whereas,independent t-test provide non-significant differences between single/mono and mixed ethnic background on ethnocentrismscore. The present study also provides significant difference in ethnocentrism score between rural and urban background university students. The mean scores show that respondents from rural background reported higher level of ethnocentric attitude and behaviour than urban background university students. Furthermore, there is significant mean score difference in ethnocentrism among different batches of university students. Above all, first year university students are more ethnocentric than other batches.

\section{Implication}

Given the findings in this study of lower ethnocentrism status can be considered as one aspect of positive human development. A central mission of the new movement in psychology is focuses on positive aspects of human development such as positive youth development, child well-being and community and youth development (Seligman \&Csikszentmihalyi, 2000). The positive human development perspective focuses on promoting positive developmental assets than deficits. The results obtained from this study revealed the positive aspects or strength of the participants rather than their deficits on ethnocentric attitude and behaviour. Thus theorists and researchers now have strong research evidence to infuse into theory. 


\section{Limitations}

The limitation of this study is it conducted entirely in institutional settings (universities) on undergraduate students who resided in campus. As a result, the findings may not represent the situation of off-campus students, the larger community and other institutional settings such as high schools, governmental and non-governmental work places in Ethiopia. Thus, the findings of the current study do not generalize beyond to undergraduate regular university students.

\section{References}

Abera, H. M. (2010). Ethnic identity and the relations of Amhara, Ormo and Tigray students at Addis Ababa University main campus (MA Thesis). In F. E. Stiftung, An Anthology of Peace and Security Research (pp. 1-67). Addis Ababa: Addis Ababa University Institute for Peace and Security Studies.

Abera, T. (2010). The influence of inter-ethnic attitude on inter-ethnic quality of interaction among AAU main campus Oromo, Amhara and Tigray students. Addis Ababa: Unpublished MA Thesis.

Asebe, R. (2007). Ethnicity and interethnic relations: the 'Ethiopian experiment' and the case of the Guji and Gedeo. University of Tromso: Unpublished MA thesis submitted for the Faculty of Social Sciences.

Belay, T. (2008). Notions of fatherhood among Ethiopian adolescents: Nature, effects and determinants. Delhi: Gagandeep Publications.

Bhawuk, D. P., \& Brislin, R. (1992). The measurement of cultural sensitivity using the concepts of individualism and collectivism. International Journal of Intercultural Relations , 16, 413-436.

Birhanu, G. (2007). Adolescents' definitions of national and ethnic identities: The case of adolescents of Amhara and Oromo ethnic groups. Addis Ababa: Addis Ababa University, Unpublished MA Thesis.

Collins, S., \& Arthur, N. (2010). Self-awareness and awareness of client cultural identities. In N. Arthur, \& S. Collins, Culture-Infused Counseling (pp. 67-102). Calgary, AB: Counseling Concepts.

Demewoz, A. (1997). Ethnocentrism and peer relationship among University students: The case of Addis Ababa University. Addis Ababa University: Unpublished MA Thesis.

Donald, R. K., \& Cindy, D. K. (2010). Us against them: Ethnocentric foundations of American opinion. Chicago and London: The University of Chicago Press.

Fowers, B. J., \& Davidov, B. J. (2006). The virtue of multiculturalism: Personal transformation, character, and openness to the other. American Psychologist , 61(6), 581-594.

Habtamu, W., Hallahmi, B. B., \& Abbink, J. (2001). Psychological modernity and attitudes to social change in Ethiopian young adults: The role of ethnic identity and stereotypes. NIRP Research for Policy Series 9, Royal Tropical Institute KIT Publisher.

Hewstone, M. W. (1985). Ethnocentrism and causal attribution in Southeast Asia. Journal of Personality and Social Psychology, 48(3), 614-623.

Hollister, E. J., \& Boivin, M. J. (1987). Ethnocentrism among free methodist leaders and students. Journal of Psychology and Theology, 15(1), 57-67.

Justen, J. R. (2009). Ethnocentrism, intercultural interaction and U.S. College students' intercultural communicative behaviors: an exploration of relationships. University of Tennessee - Knoxville: Masters Theses.

Neuliep, J. W. (2002). Assessing the reliability and validity of the Generalized Ethnocentrism Scale. Journal of Intercultural Communication Research, 31, 201-215.

Neuliep, J. W., \& McCroskey, J. C. (1997). Development of a US and Generalized Ethnocentrism Scale. Communication Research Reports, 14, 385-398. Communication Research Reports , 14, 385-398.

Phinney, J., \& Alipuria, L. (1996). At the interface of culture: Multiethnic/multiracial high school and college students. Journal of Social Psychology , 136, 139-158.

Seligman, M. P., \& Csikszentmihalyi, M. (2000). Positive psychology: An introduction. American Psychologist, $55,5-14$

Sharma, P. (1992). Scientific aptitudes as a function of social groups and educational status. Psycho Lingue, 22(2), 99-104.

Stephan, W. G., \& Rosenfield, D. (1978). Effects of desegregation on race relations and self-esteem. Journal of Educational Psychology, 70(5), 670-679.

Stephan, W. G., \& Stephan, C. W. (1991). Intermerriage: Effects on personality, adjustement, and intergroup relations in two samples of students. Journal of Marriage and the Family, 53(1), 241- 250.

Sumner, W. G. (1906). Folkways. Boston: Ginn.

Tilahun, B. (2007). Management of on group conflicts among students of diversebackground: A multicultural perspective the case of Bahr Dar University. Addis Ababa: Addis Ababa University unpublished MA thesis.

Triandis, H. C. (1977). Cross-cultural social and personality psychology. Personality and Social Psychology Bulletin , 3, 143-158.

Verkuyten, M. (2005). Ethnic group identification and group evaluation among minority and majority groups: 
Testing the multiculturalism hypothesis. Journal of Personality and Social Psychology, 88, 121-138.

Wolff, S. (2006). Ethnic conflict: A global perspective. London: Oxford University Press.

Wrench, J. S., Corrigan, M. W., McCroskey, J. C., \& Punyanunt-Carter, N. M. (2006). Religious fundamentalism and intercultural communication: the relationships among ethnocentrism, intercultural communication apprehension, religious fundamentalism, homo negativity, and tolerance for religious disagreement. Journal of Intercultural Communication Research , 35, 23-44.

Ziegler, M. (1972). Tribal stereotypes among Ethiopian students. Journal of Cross-Cultural Psychology , 3(2), 193-200. 